\title{
Blue Whale Habitat Associations in the Northwest Pacific: analysis of remotely-sensed data using a Geographic
}

\section{Information System}

\author{
Sue E. Moore \\ NOAA/Alaska Fisheries Science Center • Seattle, Washington USA
}

William A. Watkins, Mary Ann Daher

Woods Hole Oceanographic Institution. Woods Hole, Massachusetts USA

\author{
Jeremy R. Davies \\ NOAA/Northwest Fisheries Science Center - Seattle, Washington USA
}

\author{
Marilyn E. Dahlheim \\ NOAA/Alaska Fisheries Science Center - Seattle, Washington USA
}

Detection of stereotypic call sequences are now commonly used to locate blue whales (Balaenoptera musculus) in the North Pacific (e.g., Watkins et al., 2000a; Stafford et al., 1998; 2001; McDonald et al., 1995). Offshore hydrophones, such as those of the U.S. Navy Sound Surveillance System (SOSUS), have extended our monitoring capability to unprecedented spatial and temporal scales, providing the foundation for descriptions of basin-wide seasonal call patterns (Stafford et al., 1999; Clark, 1995). Consistent seasonal patterns of blue whale calling have been described for both the Northeast (NE) and Northwest (NW) regions of the Pacific basin (Watkins et al., 2000a), with clear differences in call structure suggestive of separate populations (Stafford et al., 2001). Overall, blue whale calls were two to three times more numerous in the NW region $\left(40^{\circ} \mathrm{N}\right.$ to $55^{\circ} \mathrm{N}$ latitude, between $150^{\circ} \mathrm{E}$ and $180^{\circ} \mathrm{W}$ longitude) than in other regions of the North Pacific, with consistently high calling rates from August through November (Watkins et al., 2000a: Figure 1). Monthly summaries of call occurrence and seasonal depictions of blue whale call locations (Watkins et al., 2000b) demonstrated the year-round occurrence of blue whales in the NW Pacific, with the fall-winter period showing the strongest signal. This was surprising because it belied the oft-repeated assumption that all blue whales migrate south in fall to winter, at temperate latitudes, and occupy North Pacific waters only in late spring and summer (e.g., Bowen and Siniff, 1999). Clearly, the NW Pacific presents suitable habitat for blue whales year-round, although the actual number of whales producing the calls remains unknown.

Environmental and habitat features are examined here to investigate oceanographic correlates to the seasonal variability in blue whale call rates and locations in the NW Pacific. Bathymetry and remotely-sensed oceanographic data (i.e., sea surface height, temperature and chlorophyll-a concentration) were compared with call data locations via a geographic information system (GIS). The GIS provides the means to integrate remotely sensed acoustic and satellite data over very broad temporal and spatial scales. The results serve to demonstrate the potential of GIS as a tool for the investigation of habitat associations for blue whales in a remote area and at ecological scales for which standard survey techniques are impractical.

\section{Blue Whale Call Detections}

Blue whale calls were monitored from SOSUS and other offshore hydrophones using the U.S. Navy Ocean Processing Facility (NOPF) on Whidbey Island WA, as described in Watkins et al., (2000a). Blue whale calls were identified by their characteristic long ( $>16 \mathrm{~s}$ ) sequences of stereotypic sounds with low frequency $(<20 \mathrm{~Hz})$ fundamental components (e.g., Rivers, 1997; Stafford et al., 1998). Shorter calls produced by this species were not identified. Blue whale calls are heard all year in the NW region and do not appear to fit the seasonal or geographic pattern of specialized male reproductive displays, such as the " $20-\mathrm{Hz}^{\prime}$ pulse series of fin whales or the songs of humpback whales. To 


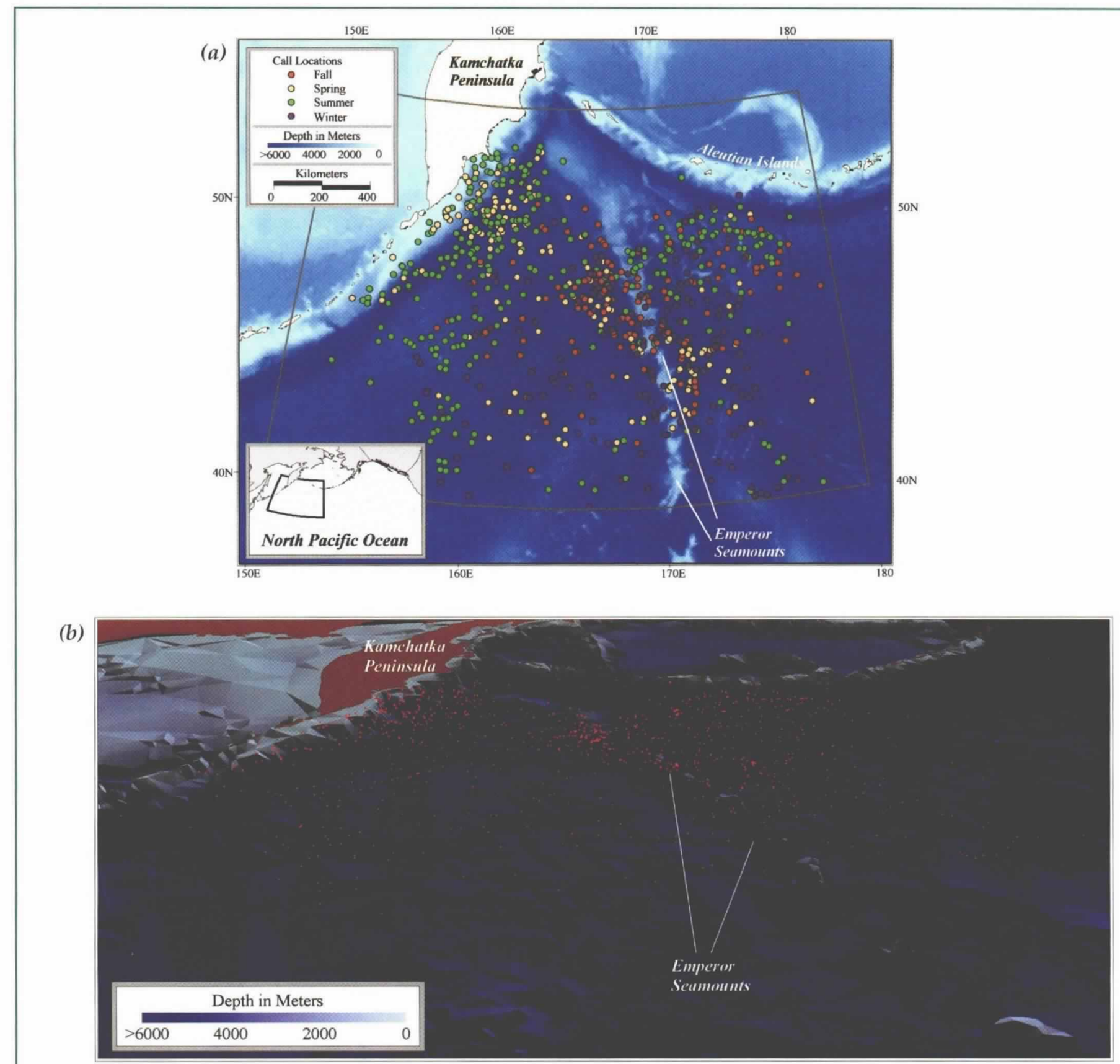

Figure 1. Locations of calling blue whales in the NW Pacific region in relation to bathymetry in planar projection (a); and in 3-D projection (b). Whale call locations are associated with the Emperor Seamounts and the steep slopes off Kamchatka Peninsula.

assess seasonal occurrence of the calls, two hydrophone arrays in the NW region were monitored over two 16-hour days each week (Watkins et al., 2000a), and a variety of additional arrays were used to refine locations for individual calling whales (Watkins et al., 2000b). Array locations and details of signal processing remain protected.

Most blue whale calls were received at only one local array, with less than $1 \%$ received over longer distances by other arrays. In addition, during periods of peak calling, there often were too many overlapping calls to permit multiple-array locations (Watkins et al., $2000 \mathrm{~b})$. Therefore, the whale locations identified here represent only those calling whales that were spatially and temporally separated from calling con-specifics and whose calls could be cross-matched on multiple hydrophone arrays; i.e., there was a downward bias in call locations when many whales were calling. Although the numbers of whale call locations do not coincide with the numbers of whales audible locally, the 
distribution pattern of call locations reflects that of the calling whales (Watkins et al., 2001). Both the seasonal pattern and locations for calling whales indicate an annual migration of many of these whales to and from southeastern waters, with the most blue whale calling in the NW Pacific during early fall and the least in late spring (Watkins et al., 2000b; 2001; Stafford et al., 2001).

Whale call locations were determined for January 1996 through August 2000 (Watkins et al., 2000b). Locations for calls matched on multiple hydrophone arrays were calculated by triangulation of directional vectors refined by sound arrival time measurements and were estimated to be accurate to within $20 \mathrm{~km}$. There appeared to be little geographic bias in the ability to locate calling whales in this region. Bathymetric data for the NW Pacific were extracted from Smith and Sandwell's (1997) measured and estimated seafloor topography. These and all other remotely-sensed data used in this study were converted to an equidistant azimuthal projection centered in the NW Pacific to minimize distortion of direction and distance within the region.

\section{Blue Whale Call Locations, Bathymetry and Surface Currents}

Plots of blue whale call locations in the NW Pacific relative to bathymetry suggest there is an association between whale distribution and the Emperor Seamounts, the steep continental slope off Kamchatka Peninsula, and the Aleutian Island chain (Figure 1). The two-dimensional map (Figure 1A) shows the association of these features with locations by season, while the three-dimensional plot of call locations (Figure 1B) depicts the seamounts and slopes as focal habitat features over the course of the year. Oceanic conditions in the NW region are dynamic, as they mark the convergence of the powerful Kuroshio Current (40 $\mathrm{Sv})$ and Kuroshio Extension (65 Sv) flowing north and eastward from Japan, and the Oyashio Current ( $35 \mathrm{~Sv}$ ) flowing south from the Bering Sea and from the Sea of Okhotsk (Pickard and Emery, 1990). The complex topographic relief (i.e., steep slopes and seamounts), dynamic boundary currents and concomitant hydrographic structure of the North Pacific likely results in frequent eddy formation in the NW region (Bush et al., 1996). Indeed, a snapshot of sea surface height (SSH) and current analysis from the $1 / 16^{\circ}$ Naval Research Laboratory Layered Ocean Model (NLOM) (Rhodes et al., 2001) demonstrates the complex eddies that can occur in this region (Figure 2). The NLOM model incorporates satellite altimetry and SST data and is run daily as an operational product by the Naval Oceanographic Office.

\section{Seasonal Call Locations, Sea Surface Temperature and Chlorophyll-a Concentration}

Sea surface temperature (SST) and chlorophyll-a (chl-a) concentration values were derived from monthly Pathfinder and SeaWiFS imagery, respectively. Images representing seasonal averages for SST $\left({ }^{\circ} \mathrm{C}\right)$ and chl-a $\left(\mathrm{mg} / \mathrm{m}^{3}\right)$ were prepared by averaging monthly pixel values for: winter $=$ December-February; spring $=$ March-May; summer $=$ June-August; fall =

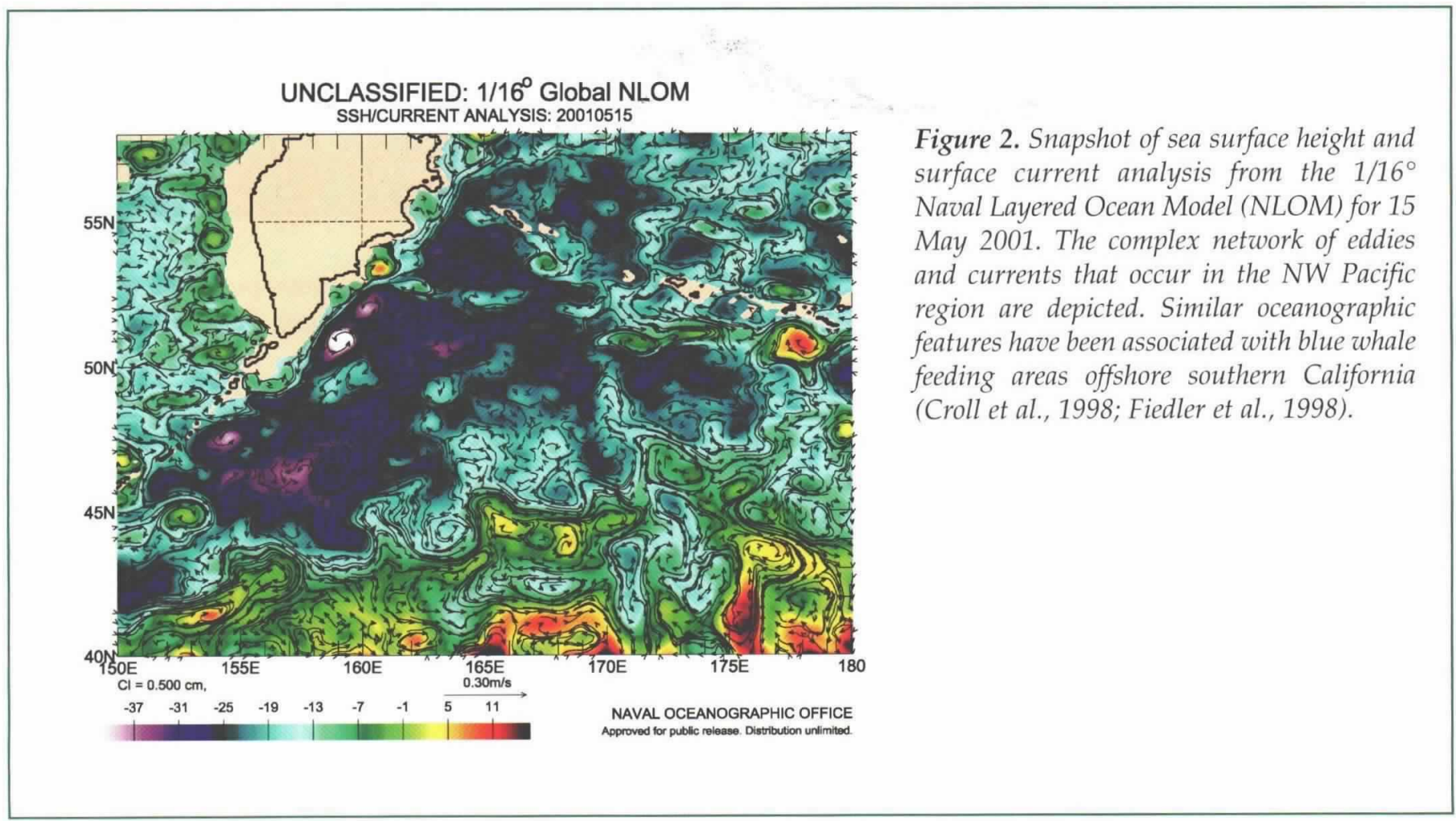



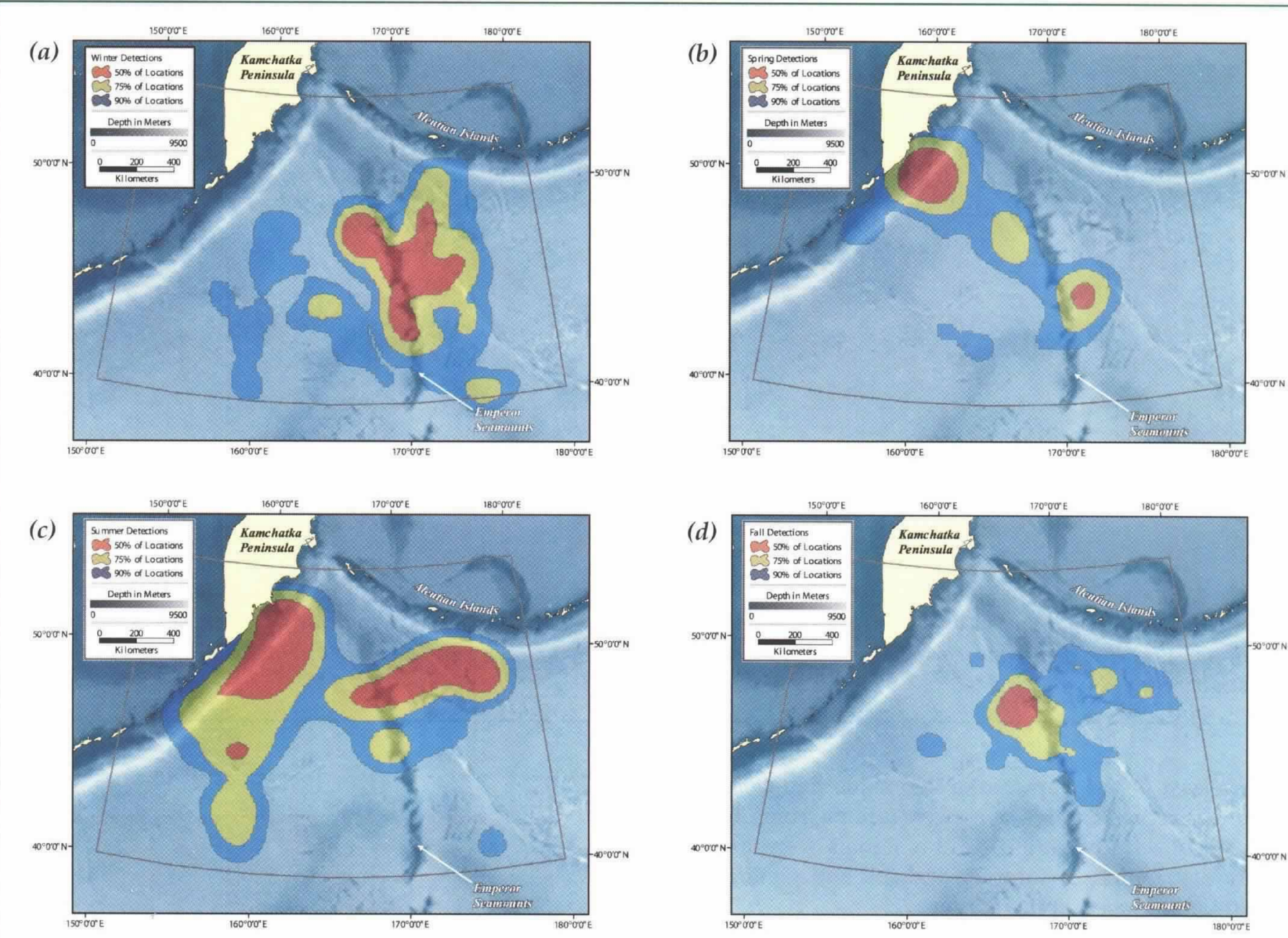

Figure 3. Seasonal blue whale call locations summarized as fixed-kernel utilization polygons depicting boundaries that comprise 50-75-90\% of the data. There is a seasonal progression of call-location concentrations over the seamounts in winter (a), the Kamchatka Peninsula and seamounts in spring (b), the Kamchatka Peninsula and waters between the seamounts and Aleutian Islands in summer (c), and the seamounts again in fall (d).

September-November. Blue whale call locations were then plotted on these images to provide seasonal snapshots of whale distribution relative to these environmental parameters.

There were clear seasonal shifts in the distribution of calling whales, as shown by call distribution polygons in Figures 3A-3D. The fixed-kernel call polygons represent a bounded region where $50 \%, 75 \%$ and $90 \%$ of all call locations occurred, and were derived by applying the Least Squares Cross Validation method (Hooge and Eichenlaub, 1997) to the seasonal subsets of the call location data. Call locations were centered over the seamounts in winter (Figure $3 \mathrm{~A}$ ), and then shifted in spring (Figure 3B) to bi-lobed areas with a large $50 \%$ concentric region near the tip of Kamchatka Peninsula and a smaller 50\% area over the seamounts. By summer (Figure 3C), call locations were broadly distributed southeast of Kamchatka Peninsula, as well as between the northern seamounts and the Aleutian chain. By fall (Figure 3D), calls were again concentrat- ed near the Emperor seamounts.

Blue whale call associations with cold water and SST fronts are illustrated in Figure 4, with call locations from August 1999 plotted with SST imagery (Figure $4 \mathrm{~A})$ and with SST gradients derived from that data (Figure 4B). Whale locations were associated with cold water and areas of sharp SST gradients, or fronts, defined as locations where the SST gradient was greater than one standard deviation from the mean gradient for the study area. Such oceanographic fronts often correspond to areas of enhanced productivity and zooplankton concentrations (Lalli and Parsons, 1993).

Blue whale call locations in the NW region were associated with high chl-a concentrations in spring, but not in other seasons presumably because phytoplankton is quickly grazed down after the spring bloom (Lalli and Parsons, 1993). For example, chl-a concentrations for May 1998 correspond well with the call locations for that month (Figure 5). The intense spring chl- 

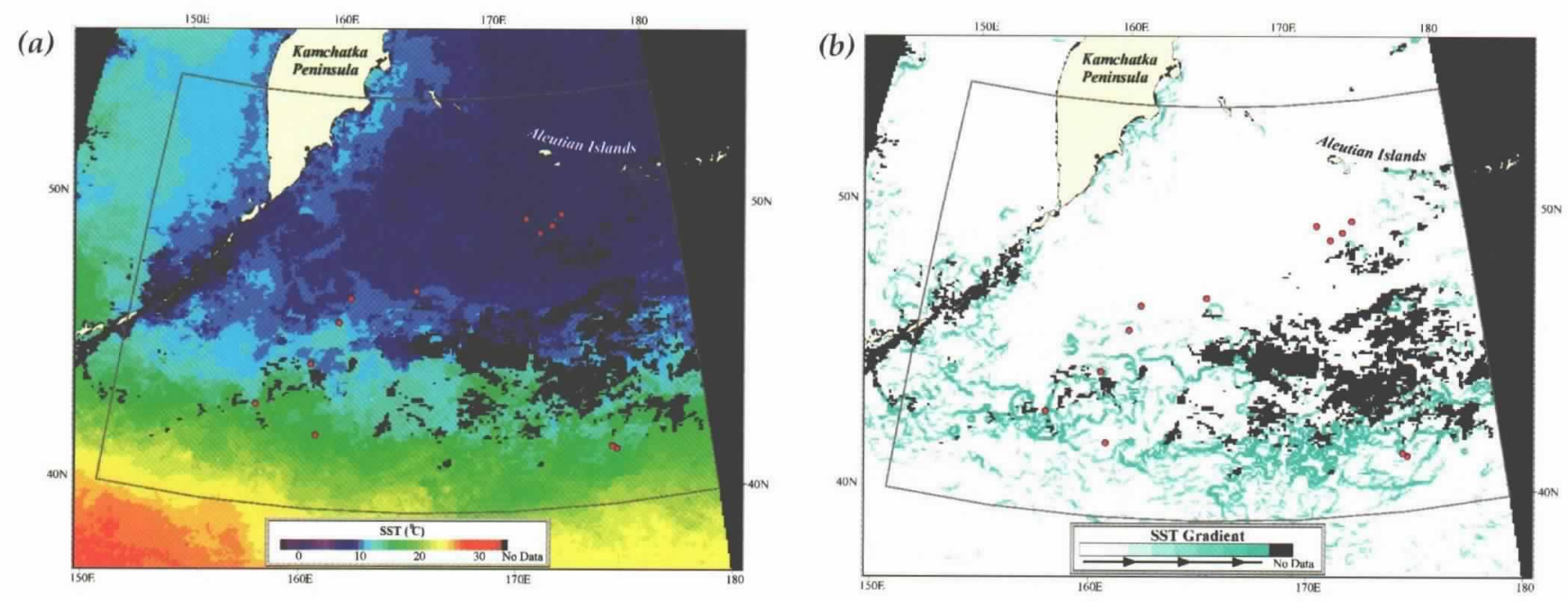

Figure 4. Blue whale call locations relative to Pathfinder SST data for August, 1999. Blue whale call locations (red dots) are depicted relative to monthly mean sea surface temperatures ( $a$ ); and relative to the SST gradient $(b)$, where fronts (depicted as turquoise) correspond to areas where the SST gradient is greater than one standard deviation from the mean gradient over the study area.

a signal east of the Kamchatka Peninsula depicted in Figure 5 is representative of concentrations from other years (in our study period). Chl-a signals were more widely distributed in summer and fall and generally were much reduced in the winter.

\section{Blue Whale Habitat Characteristics and Foraging Opportunities}

Blue whale calls in the NW Pacific were located in relatively cold and productive waters, as indicated by SST and chl-a imagery. The convergence of oceanic boundary currents combined with the complex topography of this region likely resulted in eddy formation, which can entrain and concentrate zooplankton (e.g., Huntley et al., 2000) and thereby attract the blue whales (Croll et al., 1998; Fiedler et al., 1998). The results of this remotely-based assessment are most closely comparable to two recent fine-scale studies of blue whale ecology off southern California where onsite sampling demonstrated that blue whales foraged on dense swarms of euphausiids (Euphausia pacifica and Thysanoessa spinifera) that formed downstream of areas of upwelling (Croll et al., 1998; Fiedler et al., 1998). Regions of upwelling, along the California coast and other locations with steep topography, were identified by cold SSTs, while bathymetric features downstream from the upwelling areas served to help collect and maintain large, predictable concentrations of euphausiids.

While cold SST and SST fronts seemed a consistent feature of blue whale habitat in the NW Pacific from spring through fall, chl-a was not. The relatively diffuse concentrations of chl-a observed in the NW region

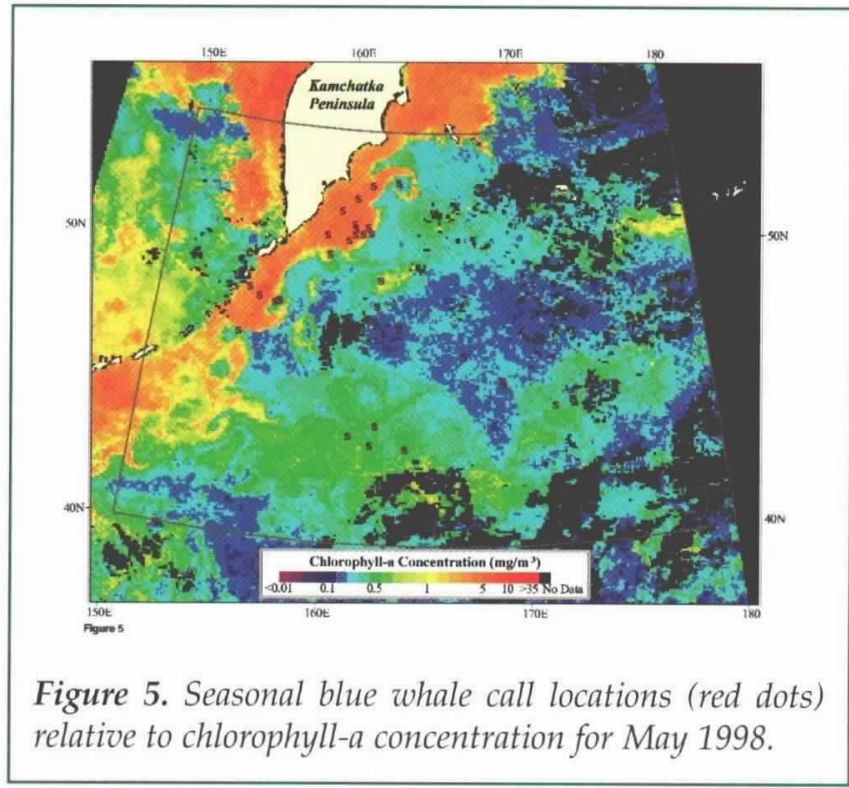

for summer and fall may be a result of the close phasing between primary and secondary productivity in the North Pacific (Lalli and Parsons, 1993). Assuming such tight phasing, chl-a concentration may not be an ideal indicator of good blue whale habitat. Indeed, short of actual zooplankton data, models combining SSH and SST, like those generated by NLOM, may be the best tools for identifying areas of high productivity in this and other regions where tight phasing and atmospheric conditions limit the use of ocean color sensors. The $1 / 16^{\circ}$ NLOM provides a new tool for remote investigation of oceanographic features. As more images become available, further investigations 
into the sea surface structure and eddy formation may provide insights to advective processes, zooplankton concentrations and the associated distribution of calling blue whales in the NW Pacific.

\section{Acknowledgements}

We thank the NASA Physical Oceanography Distributed Active Archive Center at the Jet Propulsion Laboratory, California Institute of Technology, for the production and distribution of Pathfinder SST data. We also thank the SeaWiFS Project and the Distributed Active Archive Center at the Goddard Space Flight Center for the production and distribution of SeaWiFS data, respectively. SeaWiFS activities are sponsored by NASA's Mission to Planet Earth Program. The Naval Research Laboratory's Oceanography Division at Stennis Space Center provided the real time $1 / 16^{\circ}$ NLOM results, and we thank team leaders Dr. Harley Hurlburt and Mr. Bob Rhodes, and Mr. Ole Martin Smedstad of Planning Systems, Inc., for this unique contribution to whale habitat assessment. Whale calls were monitored at the Naval Ocean Processing Facility, Whidbey Is., WA, by ex-Navy analysts experienced in identification of the whale sounds: Joseph George, Darel Martin, Scott Haga, and David Rodriguez. Whale calls were located by means of the U.S. Navy acoustic processing systems without modification. We have appreciated the encouragement and help of the Navy NOPF Commands and their dedicated personnel. Funding for the WHOI whale call analyses was from the U.S. Navy Legacy Management Office through $\mathrm{CNO} \mathrm{N} 45$. The paper was improved through incorporation of comments from three anonymous reviewers, and from Dr. Kate Stafford (AFSC/NMML). This is Contribution Number 10498 from the Woods Hole Oceanographic Institution.

\section{References}

Bowen, W.D. and D.B. Siniff, 1999: Distribution, population biology and feeding ecology of marine mammals. In: Biology of Marine Mammals, J.E. Reynolds III and S.A. Rommel, eds., Smithsonian Institution Press, Washington DC, 423-484.

Bush, A.B.G., J.C. McWilliams and W.R. Peltier, 1996: The formation of oceanic eddies in symmetric and asymmetric jets. Part II: Late time evolution and coherent vortex formation. J. Phys. Oceanog., 26, 1825-1848.

Clark, C.W., 1995: Application of US Navy underwater hydrophone arrays for scientific research on whales. Rept. Int. Whal. Commn., 45, 210-212.

Croll, D.A., B.R. Tershy, R. Hewitt, D. Demer, S. Hayes, P. Fiedler, J. Popp and V.L. Lopez, 1998: An integrated approach to the foraging ecology of marine birds and mammals. Deep-Sea Res. II, 45, 1353-1371.

Fiedler, P.C., S.B. Reilly, R.P. Hewitt, D. Demer, V.A. Philbrick, S. Smith, W. Armstrong, D.A. Croll, B.R. Tershy and B.R. Mate, 1998: Blue whale habitat and prey in the California Channel Islands. Deep-Sea Res. II, 45, 1781-1801.

Hooge, P. N. and B. Eichenlaub, 1997: Animal movement extension to ARCVIEW. ver. 1.1. Alaska Biological Science Center, U.S. Geological Survey, Anchorage, AK, USA.

Huntley, M.E., A. Gonzalez, Y. Zhu, M. Zhou and X. Irigoien, 2000: Zooplankton dynamics in a mesoscale eddy-jet system off California. Mar. Ecol. Prog. Ser., 201, 165-178.

Lalli, C.M. and T.R. Parsons, 1993. Biological oceanography: an introduction. Elsevier Science Inc., Tarrytown, New York.

McDonald, M.A., J.A. Hildebrand and S.C. Webb, 1995: Blue and fin whales observed on a seafloor array in the northeast Pacific. J. Acoust. Soc. Am., 98, $712-721$.

Pickard, G.L. and W.J. Emery, 1990: Descriptize physical oceanography, Fifth Enlarged Edition (in SI units). Pergamon Press, Oxford, UK.

Rivers, J.A. 1997: Blue whale (Balaenoptera musculus), vocalizations from the waters off central California. Mar. Mammal Sci., 13, 186-95.

Rhodes, R.C, H.E. Hurlburt, A.J. Wallcraft, E.J. Metzger, J.F. Shriver, O.M. Smedstad and A.B. Kara, 2001: A real-time $1 / 16^{\circ}$ global ocean nowcast/forecast system. NRL Review (in press), Washington, DC.

Smith, W.H.F. and D.T. Sandwell, 1997: Global seafloor topography from satellite altimetry and ship depth soundings. Science, 277, 1957-1962.

Stafford, K.M., C.G. Fox and D.S. Clark, 1998: Longrange acoustic detection and localization of blue whale calls in the northeast Pacific Ocean. J. Acoust. Soc. Am., 10, 3616-3625.

Stafford, K.M., S.L. Nieukirk and C.G. Fox, 1999: An acoustic link between blue whales in the northeast Pacific and the eastern tropical Pacific. Mar. Mamm. Sci., 15, 1258-1268.

Stafford, K.M., S.L. Nieukirk and C.G. Fox, 2001: Geographic and seasonal variation of blue whale calls in the North Pacific. J. Cet. Res. \& Mgt., 3, 65-76.

Watkins, W.A., M.A. Daher, G.M. Reppucci, J.E. George, D. L. Martin, N.A. DiMarzio and D.P. Gannon, 2000a: Seasonality and distribution of whale calls in the North Pacific. Oceanography, 13(1), 62-67.

Watkins, W.A., J.E. George, M.A. Daher, K. Mullin, D.L. Martin, S.H. Haga and N.A. DiMarzio, 2000b: Whale call data for the North Pacific, November 1995 through July 1999: Occurrence of calling whales and source locations from SOSUS and other acoustic systems. Woods Hole Oceanographic Institution Technical Report No. WHOI-00-02, 160 pp.

Watkins, W.A., M.A. Daher and J.E. George, 2001: Numbers of calling whales in the North Pacific. Woods Hole Oceanographic Institution Technical Report No. WHOI-2001-16, 37 pp. 